\title{
GENETIC CONTROL OF THE ESTERASES IN THE PROTOZOAN TETRAHYMENA PYRIFORMIS*
}

\author{
Sally Lyman Allen \\ Zoology Deparlment, University of Michigan, Ann Arbor, Mich.
}

Two years ago Markert and Møller (1959) introduced the concept of an isozyme, which they defined as one of the different molecular forms of an enzyme. They proposed that each isozyme could be controlled by a separate gene or that an isozymic series could be controlled by a single gene. Essentially the problem centers on the way in which genes control a protein: how a protein is made and how it is modified in structure and function under the influence of genotypic and microecological factors. According to the present genetic dogma the deoxyribose nucleic acid (DNA) code is translated into a ribose nucleic acid (RNA) code which specifies the sequence of amino acids in a polypeptide (see Watson, 1960; Ingram, 1960; Spiegelman, 1960). These sequences automatically determine the secondary and tertiary structures of a protein. Analysis of the genetic control of an isozyme would, therefore, further our understanding of these relationships.

Tetrahymena pyriformis possesses several different esterases, some of which form an isozymic series (Allen, 1960a). Although this study suggested that the series might be under the control of a single locus, only recently has a definitive answer been obtained. This report will present these observations and also evidence for the genetic control of other members of the family of esterases. The behavior of the isozymes in heterozygotes suggests that they are also under epigenetic control (Nanney, 1958) and that the pattern of nuclear differentiation and vegetative assortment is probably similar to that observed for other loci in this organism.

\section{Materials and Methods}

A detailed description of the materials and some of the methods employed in this study was given in an earlier report (Allen, 1960a). Representatives of four of the inbred strains, A, B, C and D, of variety 1 of $T$. pyriformis were sampled for their esterases. In the present study two of these strains, B and C, served as the source of the parental cultures used in making crosses. They are now in the 11th and 10th generations of inbreeding, respectively. The origins of these strains were described by Nanney (1959).

All crosses were made from cultures grown on 1 per cent proteose-peptone at $30^{\circ} \mathrm{C}$. using sterile technique. The crosses were made in sterile glass-distilled water, and the mating pairs were separately isolated into depression slides containing peptone. In some crosses the exconjugants were separated. The culture that developed was tubed up in peptone, and after the plateau phase of growth had been reached, it was transferred to $250 \mathrm{ml}$. Erlenmeyer flasks with $100 \mathrm{ml}$. of peptone, adjusted to $\mathrm{pH}$ 7.0. Extracts were made after 5 days of growth (plateau) at $30^{\circ} \mathrm{C}$. However, before any culture was used,

* The work described in this paper was supported by Research Grant C-3545 from the National Cancer Institute, Public Health Service, Bethesda, Md. 
the pair giving rise to it was carefully screened for immaturity, a sign that conjugation has been completed in the pair. Only immature cultures were used.

Crude extracts of concentrated cells from $100 \mathrm{ml}$. of culture were prepared by repeated freeze-thawing. In a few experiments preparations of cilia from cultures of strains $B$ and $C$ were made according to the method outlined by Preer and Preer (1959, p. 90). The cilia preparations were also frozen-thawed.

The electrophoretic separations were carried out in starch gels using a borate buffer system at $p \mathrm{H} 7.5$ except in a few experiments in which a $p \mathrm{H}$ of 8.5 or 9.5 was used. The application of the zymogram technique (Hunter and Markert, 1957) to T. pyriformis was described earlier (Allen, 1960a). For histochemical determinations $\alpha$-naphthyl acetate, $\beta$-naphthyl acetate, $\alpha$ naphthyl propionate, and $\alpha$-naphthyl butyrate were used as substrates, and the stable diazotate of $4^{\prime}$-amino-2' $\mathbf{2}^{\prime} \mathbf{5}^{\prime}$-dimethoxybenzanilide (Fast Blue RR)* was used as dye-coupler. In some experiments starch strips were preincubated in eserine sulfate, at a final concentration of $10^{-4} M$. The substrates, $\alpha$-naphthyl propionate and $\alpha$-naphthyl butyrate, only, were used for the identification of the E-1 and E-2 esterases in the progeny of crosses. For facilitating the identification of the E-1 esterases one of the starch strips was exposed to a reaction mixture containing $\alpha$-naphthyl propionate, Fast Blue RR, and sodium taurocholate, at a final concentration of $1^{-2} M$. After 3 to 4 hours of incubation in the reaction mixtures, the starch strips were removed and photographed with a Polaroid Land camera. In a few experiments the intensity of staining of the E-1 esterases was measured directly from starch strips (using starch poured 1 hour before use) with a modified Photovolt Densitometer. $\dagger$

The localization studies were performed on air-dried preparations on clean slides. No fixatives and no egg albumin were used, since they were found to destroy the patterns of localization. The same histochemical reagents used above were also used here, except that the stable diazotate of o-dianisidine (Fast Blue BN) $\ddagger$ was used as dye-coupler. The slides were incubated in the reaction mixtures for varying lengths of time, but the optimum incubation time was $35 \mathrm{~min}$. The slides then were rinsed in distilled water and mounted in 1 per cent glycerine jelly.

\section{The Esterases of Variety $1 T$. pyriformis}

The proteins of variety 1 of $T$. pyriformis can be resolved into a number of zones having esterase activity (FIGURE 1). These zones can be separated into two classes on the basis of substrate specificity and reaction to eserine sulfate and sodium taurocholate. At a $p \mathrm{H}$ of 7.5 during the electrophoretic separation the class I esterases include two groups of isozymes: the B group with four to five isozymes, which migrates towards the cathode, and the $\mathrm{C}$ group with four isozymes, which migrates towards the anode. At $p \mathrm{H} 8.5$ and 9.5 each group contains a pair of isozymes (FIGURE 2). The B group is found in several inbred strains (A, B, and D) while the $\mathrm{C}$ group is limited to strain $\mathrm{C}$ (FIGURE 3). The class I esterases are inhibited by $10^{-4} M$ eserine sulfate and activated

* General Dyestuff Company, New York, N.Y.

$\dagger$ Model 525, modified by Robert L. Hunter in cooperation with the Photovolt Corporation, New York, N.Y.

† General Dyestuff Company, New York, N.Y. 
by $10^{-2} M$ sodium taurocholate (FIGURE 4). They split $\alpha$-naphthyl propionate, $\alpha$-naphthyl acetate and $\beta$-naphthyl acetate, in order of efficiency, but split $\alpha$-naphthyl butyrate very poorly, if at all (FIGURE 5). Visual inspection shows that the activation by taurocholate depends upon the substrate present. The order of activation was the following: propionate $\gg$ butyrate $>\alpha$-acetate $>\beta$-acetate. The class I esterases will be referred to hereafter as the E-1 esterases.

\section{CHARACTERIZATION OF ESTERASES IN T. PYRIFORMIS, VARIETY 1}

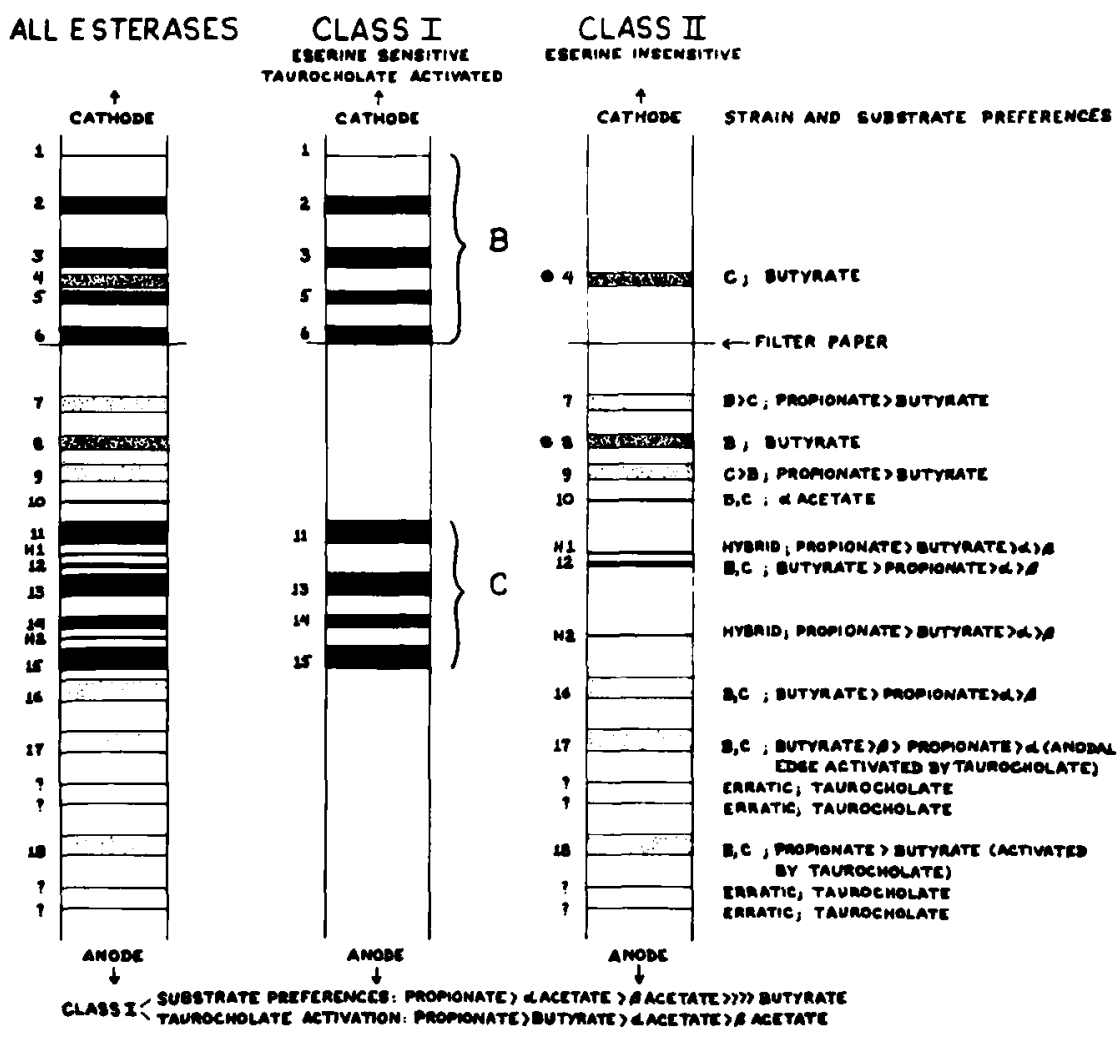

Figure 1. Diagram of esterases in variety 1 of $T$. pyriformis.

The class II esterases are a family of different enzymes, whose substrate preferences are indicated on the right of FIGURE 1. Two of these esterases at zones 4 and 8 only split $\alpha$-naphthyl butyrate. They show strain differences, the esterase at zone 8 being found in strain $B$ and the esterase at zone 4 being found in strain C. Electrophoretic separation at $p \mathrm{H} 8.5$ shows little change in position over separation at $p \mathrm{H} 7.5$ (FIGURE 6). Hereafter, these two esterases will be referred to as the E-2 esterases.

The E-1 esterases are of considerable interest since they are made up of an isozymic series. An earlier report (Allen, 1960a) showed that all members of 


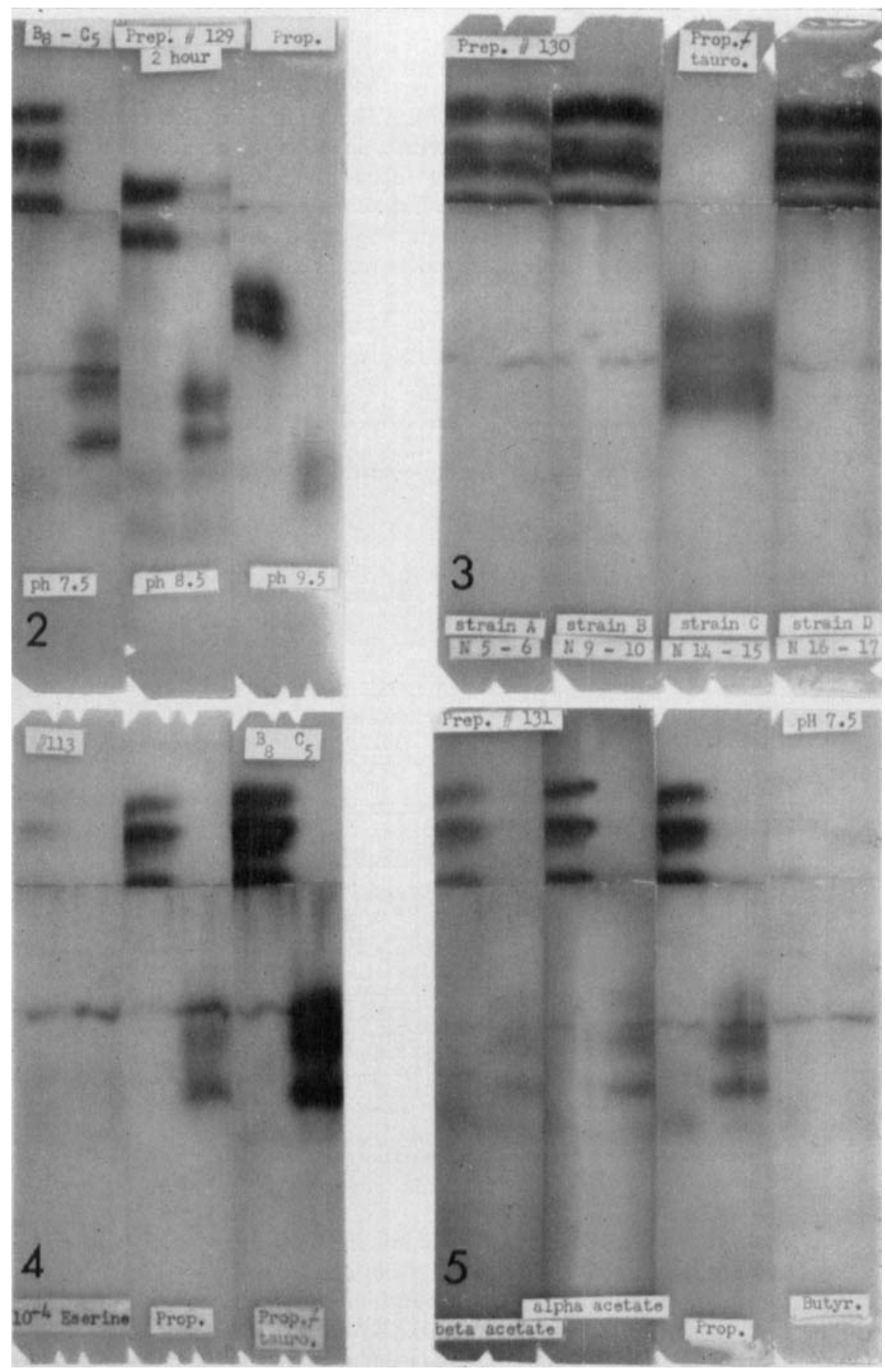

FIGORE 2. Effect of $p H$ on migration of E-1 esterases (B on left, $C$ preparation on right of same starch columns). Substrate: $\alpha$-naphthyl propionate. Incubated 2 hours.

FIgure 3. B and C groups of E-1 esterases in four inbred strains. Substrate: $\alpha$-naphthyl propionate with sodium taurocholate. Incubated 4 hours.

Figure 4. Inhibition and activation of $\mathbf{E}$-1 esterases (B on left, $\mathrm{C}$ on right) with $\alpha$-naphthyl propionate as substrate. Incubated 3 hours.

FIgURE 5. Substrate specificities of E-1 esterases (B on left, $C$ on right). Incubated 4 hours. 
an isozymic group are present in a single cell as determined by clonal analysis. Also, all members are present under a variety of growth conditions, but they differ in their intensity of activity. If cells are starved preparatory for mating, the activities of the anodal isozymes in each group are enhanced. If cells are grown at $16^{\circ} \mathrm{C}$. for one to three weeks, then the activities of the cathodal isozymes in each group are enhanced. This pattern is also observed in the heterozygote (which contains both groups) and occurs in each group of isozymes. If cultures are grown for progressively longer periods of time before extractions are made, a complex sequence of activities is observed in each group as a function of the growth cycle.

Preliminary studies suggest that isozymic activities may also vary in different parts of the cell, although some difficulty in precise definition may be anticipated depending upon the degree of solubility of these esterases. Cilia preparations have a different pattern of activities than extracts of the whole cell (FIGURE 7). Although the difference is only quantitative in these preparations, one isozyme in each group appears to be greatly enhanced. In a closely related ciliate (Tetrahymena geleii S), Seaman (1951) demonstrated a specific acetylcholinesterase associated with the fibrillar system of the pellicle. Thus cell fractionation procedures may prove very useful in defining the different isozymes. With further refinement of these techniques and extension of this type of analysis to include many more cell fractions it may even be possible to achieve qualitative differentiation of the isozymes.

An attempt to find different patterns of intracellular localization using whole cells will not be fruitful in view of the failure to differentiate the esterases as to class or strain, using the localization techniques (Allen, 1958). However, striking but similar differences in pattern were observed in the total esterase picture of all strains during the course of the growth cycle. These observations may be pertinent in the present context, since they do demonstrate significant shifts in site of activity within the cell. During the logarithmic phase of the growth cycle the localizations are confined to discrete "vesicles" in a perinuclear position (FIGURE 8) and, in dividing cells, the perinuclear orientation is retained. The "cortex" is poorly developed and lacks activity. The activity per cell is uniform within the cell population. When cells reach plateau the vesicles extend from the perinuclear position to the posterior of the cell (FIGURE 9). The cortex is fully developed, very active, and has a characteristic architecture: from indentations in the cell membrane run "fibrillae" (these may represent overlapping layers of cilia in a flattened preparation); they occur at regular intervals perpendicular to the cell surface. Below these indentations in the cell membrane, which is active enzymatically, are granules that are also active. If focussed on the surface of the cell, the pattern of activities is similar to silver-line preparations, which outline the kinetal system. Dipping the slides in ethanol removes the cortical structure entirely. During the stationary period the most active cells show a well-developed cortex, and the vesicles fill the cytoplasm of the cell (FIGURE 10). The cell population, however, shows extreme variability both in cell size and activity, and these are correlated.

These changes represent a complex of the activities of many different esterases, yet they demonstrate that certain sites within the cell are esterase-positive and 


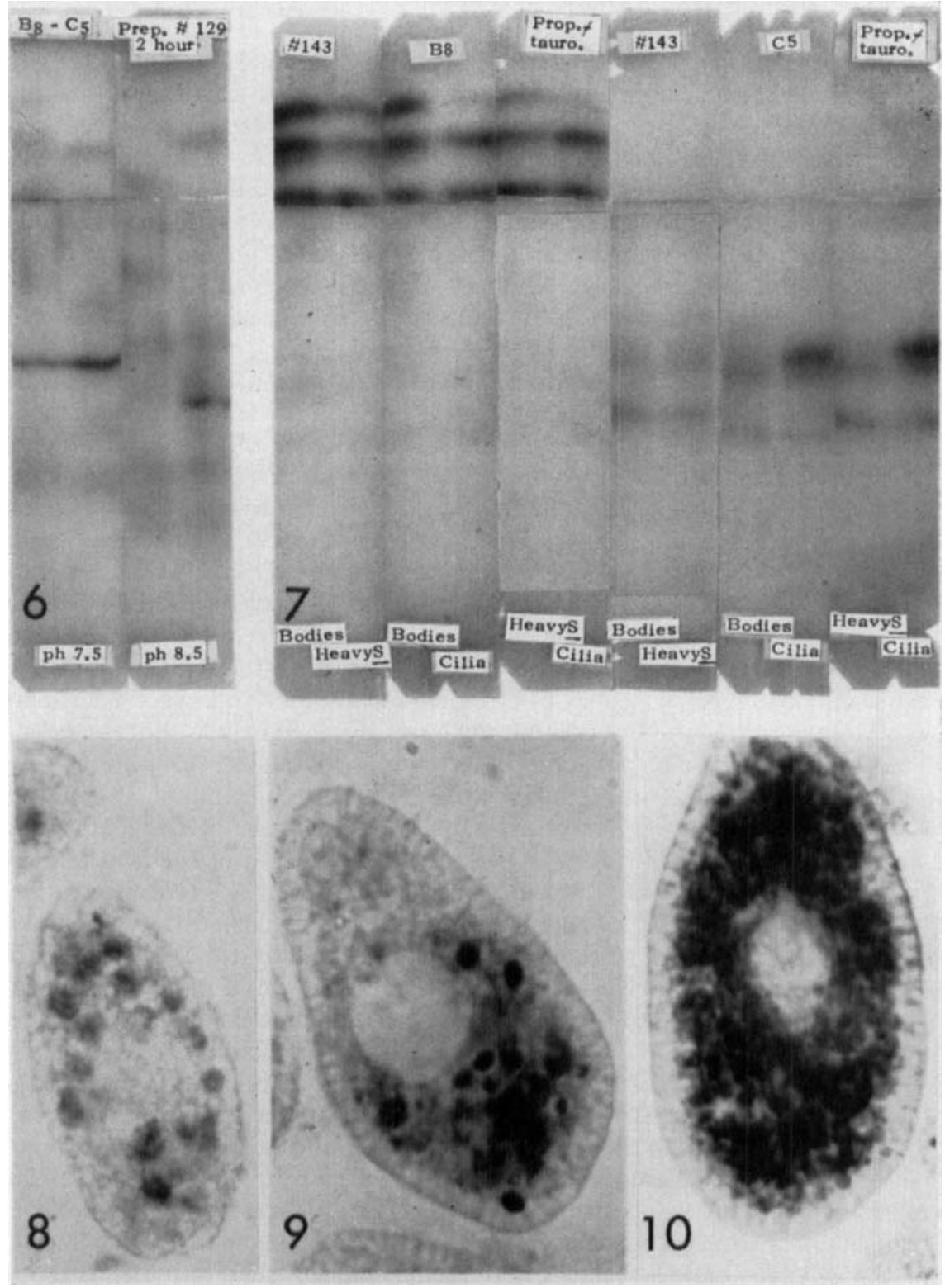

FigurE 6. Effect of $p \mathrm{H}$ on migration of $\mathrm{E}-2$ esterases (B on left, $\mathrm{C}$ on right). Substrate: $\alpha$-naphthyl butyrate. Incubated 2 hours.

FIGURE 7. Comparison of cilia fractions with body fractions (B set on left, $\mathrm{C}$ set on right). Compact pellet is labeled "bodies"; flocculent precipitate immediately above compact pellet is labeled "Heavy S"; milky supernatant above is labeled "Cilia." Substrate: $\alpha$-naphthyl propionate with sodium taurocholate. Incubated 4 hours.

Figure 8. Intracellular localization of esterase activity during logarithmic phase of growth cycle. Substrate: $\alpha$-naphthyl acetate. $\times 760$.

FiguRe 9. Intracellular localization of esterase activity during plateau phase of growth cycle. Substrate: $\alpha$-naphthyl acetate. $\times 760$.

Figure 10. Intracellular localization of esterase activity during stationary phase of growth cycle. Substrate: $\alpha$-naphthyl acetate. $\times 760$. 
that their activities change depending upon whether the cells are actively dividing or are merely growing in size. From these observations and the preliminary studies of cell fractions, it seems that a microtopological approach might be very helpful towards understanding the nature of an isozyme. It might even be possible to localize each isozyme of a group to a different cell structure.

\section{Genetic Studies}

Before presenting the results of the genetic studies, the expectations of conjugation in $T$. pyriformis will be briefly reviewed (FIGURE 11). Tetrahymena possesses one macronucleus and one micronucleus. The macronucleus contains many chromosome sets organized into physiological units called subnuclei (Allen and Nanney, 1958) that control the vegetative phenotypes of the

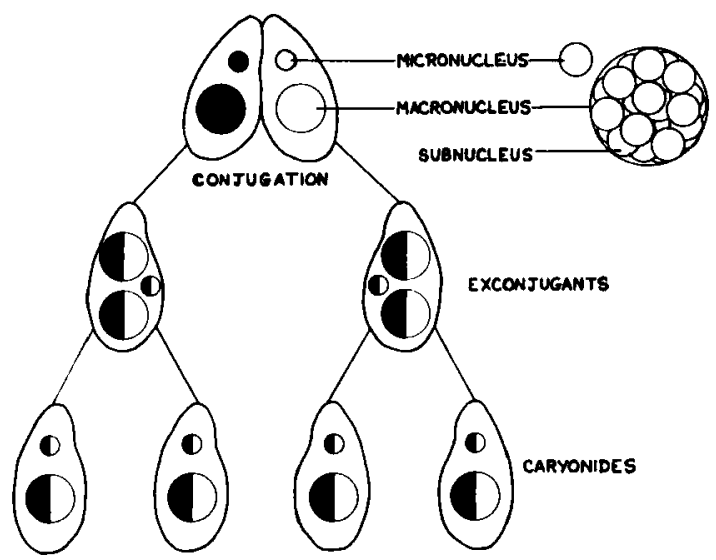

FIGURE 11. Diagram of conjugation in T. pyriformis.

cell. During conjugation the old macronucleus is discarded, and new ones form from the products of the zygotic nucleus. In each conjugant of a mating pair the micronucleus undergoes meiosis, giving rise to four haploid nuclei, three of which disintegrate. The remaining nucleus divides mitotically to give rise to the migratory and stationary pronuclei. Reciprocal fertilization results in a zygotic nucleus that is diploid and identical in genotype in the two exconjugants. Different pairs may differ in genotype. Thus, after a cross is made, each pair is isolated into a separate container. Genetic ratios are obtained from the distributions of phenotypes observed in the different pairs. For some characters differences in phenotype may be found within the pair (see Sonneborn, 1957): between exconjugants and even between the two daughter cells (or sister caryonides) of the same exconjugant. A difference in phenotype between exconjugants is associated with differences in cytoplasmic factors, whereas a difference in phenotype between sister caryonides is associated with nuclear differentiation.

The phenotypes of the E-1 esterases are a pair characteristic although, as will be shown below under the E-1 Heterozygote, the phenotype of the heterozygote 
is probably determined at the level of the caryonide. The results of several types of crosses are presented in TABLE 1. Crosses within a strain $(B \times B$ or $\mathrm{C} \times \mathrm{C}$ ) give rise to pairs possessing only the group of isozymes characteristic of the strain. In genuine heterozygotes produced in a cross of $\mathrm{B} \times \mathrm{C}$ all eight or nine isozymes are present; that is, all the isozymes of each group, so that these heterozygotes may be classified as $\mathrm{E}-1 \mathrm{~B}+\mathrm{C}$ in phenotype. Unlike the esterases of maize (Schwarz, 1960) no hybrid molecules are formed.

Some exceptional pairs will be noted in the F1 generation. These are homozygotes: for the E-1 esterases, but also for characters at four different loci, some of which are unlinked (Allen, $1960 \mathrm{~b}$ and unpublished). They arise as a result of genomic exclusion during conjugation, with members of the $\mathrm{C}$ strain varying in their capacity to produce this effect. As a matter of fact, the first crosses made in the genetic analysis of the esterases (Allen, 1960a) involved a member of the $\mathrm{C}$ strain, which produces almost 100 per cent transmission of all genes

TABle 1

Breeding Behavior of E-1 Esterases

\begin{tabular}{|c|c|c|c|c|}
\hline \multirow{2}{*}{ Cross } & \multirow{2}{*}{ No. pairs tested } & \multicolumn{3}{|c|}{ Esterases } \\
\hline & & $\mathrm{B}+\mathrm{C}$ & B & $\mathrm{C}$ \\
\hline $\begin{array}{c}\mathrm{B} \times \mathrm{B} \\
\mathrm{C} \times \mathrm{C} \\
\mathrm{B} \times \mathrm{C} \\
\mathrm{B} / \mathrm{C} \times \mathrm{B} / \mathrm{C} \\
\mathrm{B} / \mathrm{C} \times \mathrm{B} / \mathrm{B} \\
\mathrm{B} / \mathrm{C} \times \mathrm{C} / \mathrm{C}\end{array}$ & $\begin{array}{r}10 \\
22 \\
28 \\
22 \\
177 \\
59 \\
40\end{array}$ & $\begin{array}{c}0 \\
0 \\
22 \\
8 \\
88 \\
33 \ddagger \\
24\end{array}$ & $\begin{array}{c}10 \\
0 \\
3^{*} \\
14 \dagger \\
45 \\
26 \\
0\end{array}$ & $\begin{array}{r}0 \\
22 \\
3^{*} \\
0 \\
44 \\
0 \\
16\end{array}$ \\
\hline
\end{tabular}

* Homozygous at $E-1, E-2, m i$ and probably $H$ locus.

$\dagger$ The 14 "B" pairs were probably homozygous for B alleles at $E-1, E-2$, and $m t$ loci.

¥ Two pairs, phenotypically " $C$ " tested as heterozygotes.

from the other parent in the cross! The basis of this phenomenon is, at present, unknown, since cytological observation shows that $C$ cells are present in the mating pairs and both exconjugants are recovered, yet conjugation appears to be normal in many more pairs than expected. Whatever its ultimate basis, this phenomenon has presented a major stumbling block in the analysis of all characters derived from the $\mathrm{C}$ strain.

Fortunately, some genuine heterozygotes are produced in crosses to the $\mathrm{C}$ strain. These heterozygotes breed normally, and good genetic ratios are obtained in the F2 and some backcross generations. In the F2 generation three classes of pairs were observed (FIGURE 12) in a 2:1:1 ratio-88 B + C: $45 \mathrm{~B}$ : $44 \mathrm{C}$. The backcross to strain B yields two classes of pairs (FIGURE 13) in a 1:1 ratio- $33 \mathrm{~B}+\mathrm{C}: 26 \mathrm{~B}$, and the backcross to strain $\mathrm{C}$ yields two different classes of pairs (FIGURE 14) in an approximate 1:1 ratio-24 B + C: $16 \mathrm{C}$.

The results of testcrossing seven F2 segregants appear in TABLE 2. The two E-1B F2 segregants produced only B offspring, the two E-1C F2 segregants produced only C offspring, while the three E-1B + C F2 segregants produced all three classes of pairs in approximate 2:1:1 ratios. The exconjugants were 


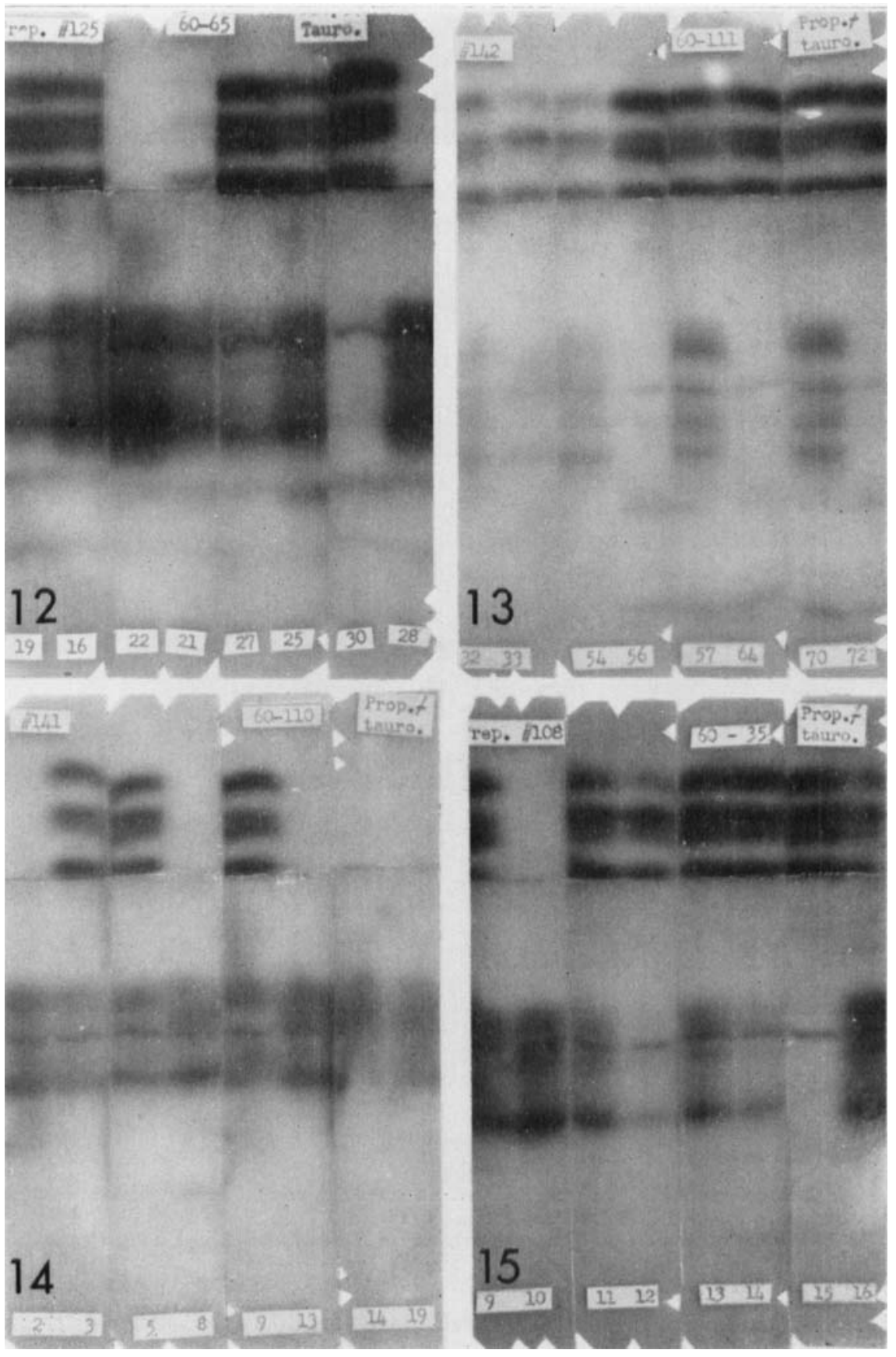

FIGURE 12. E-1 esterases of 8 F2 pairs. Substrate: $\alpha$-naphthyl propionate with sodium taurocholate. Incubated 4 hours.

FIGURE 13. E-1 esterases of 8 backcross pairs $(B / C \times B / B)$. Substrate: $\alpha$-naphthyl propionate with sodium taurocholate. Incubated 4 hours.

FIGURE 14. E-1 esterases of 8 backcross pairs $(B / C \times C / C)$. Substrate: $\alpha$-naphthyl propionate with sodium taurocholate. Incubated 4 hours.

Figure 15. Eight subclones derived from an E-1B + C heterozygote. Substrate: $\alpha$ naphthyl propionate with sodium taurocholate. Incubated $\mathbf{4}$ hours. 
separated in the starred crosses and, except for the exconjugants of a heterozygous pair, the two were phenotypically alike. Exconjugants of heterozygotes varied quantitatively in their activities of the two groups of isozymes and occasionally qualitatively, that is, one of the exconjugants would possess activity for only one of the two groups of isozymes.

TABLE 2

TESTCROSSES OF F2 SEgREgants FOR E-1 Esterases

\begin{tabular}{c|c|c|c|c}
\hline \hline \multirow{2}{*}{ Phenotypes } & No. pairs tested & \multicolumn{3}{|c}{ Esterases } \\
\cline { 2 - 4 } & $8^{*}$ & B + C & B & C \\
\hline B & $5^{*}$ & 0 & 8 & 0 \\
B & $8^{*}$ & 0 & 5 & 0 \\
C & $8^{*}$ & 0 & 0 & 8 \\
C & $12^{*}$ & 0 & 0 & 8 \\
B + C & $8^{*}$ & 5 & 5 & 2 \\
B + C & $\frac{21}{29}$ & $\frac{10}{5}$ & $\frac{4}{5}$ \\
& 55 & 25 & 21 & 9 \\
\hline
\end{tabular}

* Exconjugants separated.

TABle 3

Breeding Behayyor of E-2 Esterases

\begin{tabular}{|c|c|c|c|c|}
\hline \multirow{2}{*}{ Cross } & \multirow{2}{*}{ No. pairs tested } & \multicolumn{3}{|c|}{ Esterases } \\
\hline & & $B+C$ & B & $\mathbf{C}$ \\
\hline $\begin{array}{c}\mathbf{B} \times \mathbf{B} \\
\mathrm{C} \times \underset{\mathrm{C}}{\mathrm{B} \times \mathrm{C}} \\
\mathrm{B} / \mathrm{C} \times \mathrm{B} / \mathrm{C} \\
\mathrm{B} / \mathrm{C} \times \mathrm{B} / \mathrm{B} \\
\mathrm{B} / \mathrm{C} \times \mathrm{C} / \mathrm{C}\end{array}$ & $\begin{array}{l}10 \\
22 \\
28 \\
22 \\
39 \\
40 \\
40\end{array}$ & $\begin{array}{r}0 \\
0 \\
22 \\
8 \\
20 \\
18 \\
26\end{array}$ & $\begin{array}{c}10 \\
0 \\
3^{*} \\
14 \dagger \\
11 \\
22 \\
0\end{array}$ & $\begin{array}{c}0 \\
22 \\
3^{*} \\
0 \\
8 \\
0 \\
14\end{array}$ \\
\hline
\end{tabular}

* Homozygous at $E-1, E-2, m t$ and, probably, $H$ locus.

$\dagger$ The 14 "B" pairs were probably homozygous for B alleles at $E-1, E-2$, and $m t$ loci.

The genetic data are consistent with the hypothesis that the two groups of isozymes are under the control of alleles at a single locus or at a cluster of closely linked loci. This locus (or region) will be designated as the $E-1$ locus. The B strain is homozygous for the $E-1^{\mathrm{B}}$ allele, the C strain for the $E-1^{\mathrm{C}}$ allele. The heterozygote $\left(E-1^{B} / E-1^{C}\right)$ has the potentiality of producing both groups of isozymes.

A second locus (E-2) governs the E-2 esterases, a conclusion reached from the results of the crosses shown in TABLE 3. The E-2B esterase is produced by 
$E-2^{\mathbf{B}} / E-2^{\mathbf{B}}$ homozygotes, the E-2C esterase by $E-2^{\mathbf{C}} / E-2^{\mathbf{C}}$ homozygotes. The heterozygote $\left(E-2^{\mathrm{B}} / E-2^{\mathrm{C}}\right)$ produces both esterases $(\mathrm{E}-2 \mathrm{~B}+\mathrm{C})$, but each esterase has about one half the activity of that of the homozygote. There is a suggestion that the $E-2$ heterozygote may also show variability in expression of the two esterases, but the pattern of variability is, as yet, not well documented.

Linkage tests of the $E-1$ and $E-2$ loci indicate independent assortment (TABLE 4). Both types of esterases were scored in the two backcross generations, and no significant deviation from the expected 1:1:1:1 ratio occurred. Linkage tests are in progress for the mating type $(m t)$ locus and the $E-1$ and $E-2$ loci, but the data thus far are inconclusive. Tests have not, as yet, been initiated on the esterase loci and the $H$ (serotype) locus, which is known not to be linked with the $m t$ locus (Nanney, 1960b).

TABLE 4

INDEPENDENCE OF E-1 AND E-2 ESTERASES

\begin{tabular}{|c|c|c|c|c|c|}
\hline Cross & $\begin{array}{l}\mathrm{E}-1 \mathrm{~B}+\mathrm{C} / \\
\mathbf{E}-2 \mathrm{~B}\end{array}$ & $\underset{E-2 B}{E-1 B}+C /$ & $\underset{E-2 B}{E-1 B}+C$ & E-1B/E-2B & Total \\
\hline \multirow[t]{2}{*}{$\mathrm{B} / \mathrm{C} \times \mathrm{B} / \mathrm{B}$} & 11 & 11 & 7 & 11 & 40 \\
\hline & $\begin{array}{c}\mathrm{E}-1 \mathrm{~B}+\mathrm{C} / \\
\mathrm{E}-2 \mathrm{~B}+\mathrm{C}\end{array}$ & $\underset{\mathbf{E}-2 \mathbf{C}}{\mathbf{E}-1 \mathbf{B}}+\mathbf{C} /$ & $\underset{E-2 B}{E-1 C /} C$ & E-1C/E-2C & \\
\hline $\mathrm{B} / \mathrm{C} \times \mathrm{C} / \mathrm{C}$ & 14 & 10 & 12 & 4 & 40 \\
\hline
\end{tabular}

\section{The E-1 Heterozygole}

Although the $E-1$ heterozygote has the potentiality of producing both groups of isozymes, it varies in its expression of the two groups. Quantitative variation-and even qualitative variation - occurs between the exconjugants of a heterozygous pair. This variation is also observed within a single caryonide. When single cells were isolated from a caryonidal culture, the subclones showed considerable variability in their enzymatic activities (FIGURE 15), although the total activities of the four or eight isozymes present approached a common value. Some subclones had only $B$ isozymes, some had only $C$ isozymes, while others had some B and some C activity. The E-1B or E-1C subclones were stable, but the $\mathrm{E}-1 \mathrm{~B}+\mathrm{C}$ subclones were metastable and gave rise to $\mathrm{E}-1 \mathrm{~B}+$ $\mathrm{C}$ and E-1B and/or E-1C cell lineages. Most of the cell lineages were E-1B + $\mathrm{C}$, but the frequency of the three types varied with different $\mathrm{E}-1 \mathrm{~B}+\mathrm{C}$ subclones.

The distribution of subclones from one E-1B $+\mathrm{C}$ caryonide is depicted graphically (FIGURE 16). The graphs are based on Densitometer recordings. In general, the activity of a single isozyme was proportionate to the activity of a group, but in order to eliminate slight variations due to small differences in rates of cell division between cultures, which would influence the activity of a given isozyme, the group activities were calculated. The activities of each group were totaled, then the percentage of $\mathrm{C}$ group activity was determined for each subclone. Thus a subclone with only B activity would have a " 0 " per cent 
value, while one with only $C$ group activity would have a " 100 " per cent value. Those with some $\mathbf{C}$ group and some $\mathbf{B}$ group activities have intermediate values. Treatments of two kinds (starvation for one week in distilled water before isolating single cells into peptone; or growth of isolates at $16^{\circ} \mathrm{C}$. for three weeks before transferring the cultures to flasks at $30^{\circ} \mathrm{C}$.) had no effect on the distri-

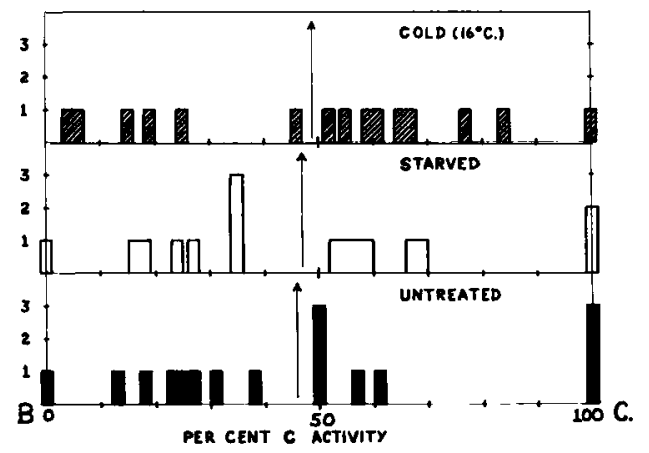

FIGURE 16. Lack of effect of two treatments on distribution of subclones derived from an $\mathrm{E}-1 \mathrm{~B}+\mathrm{C}$ heterozygote. Arrows represent means of distribution.

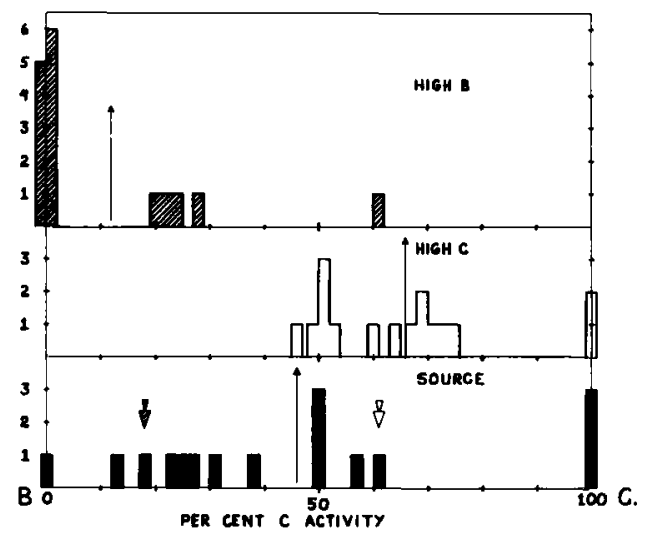

FIGURE 17. Distributions of lineages derived from different $\mathrm{E}-1 \mathrm{~B}+\mathrm{C}$ subclones. Arrows pointing up represent means of distributions; sources of two top distributions indicated by arrows pointing down.

butions of subclones that resulted. The mean activities were similar in all three arrays of subclones.

When E-1B $+\mathrm{C}$ subclones with different percentages of $\mathrm{C}$ activity were deliberately selected and expanded, the resulting distributions of cell lineages were markedly dissimilar (FIGURE 17). Two subclones were selected from the array shown on the bottom graph. The middle graph records the distribution of cell lineages obtained from a subclone with 62 per cent $\mathrm{C}$ activity, the top graph that obtained from a subclone with 18 per cent $\mathrm{C}$ activity. Only one stable type of cell lineage (either E-1B or E-1C) was produced by these subclones with eccentric activities. 
Adequate kinetic data are not available for the E-1 esterases; however, similar patterns of vegetative assortment were observed at the $m i$ locus (Allen and Nanney, 1958) and at the $H$ serotype locus (Nanney and Dubert, 1960). These patterns of vegetative assortment were interpreted in terms of a particulate segregation model, developed by Schensted (1958). The macronucleus was postulated to contain diploid subnuclei, which could differentiate to yield a heterogeneous macronucleus. Stable cell lines would arise as a consequence of
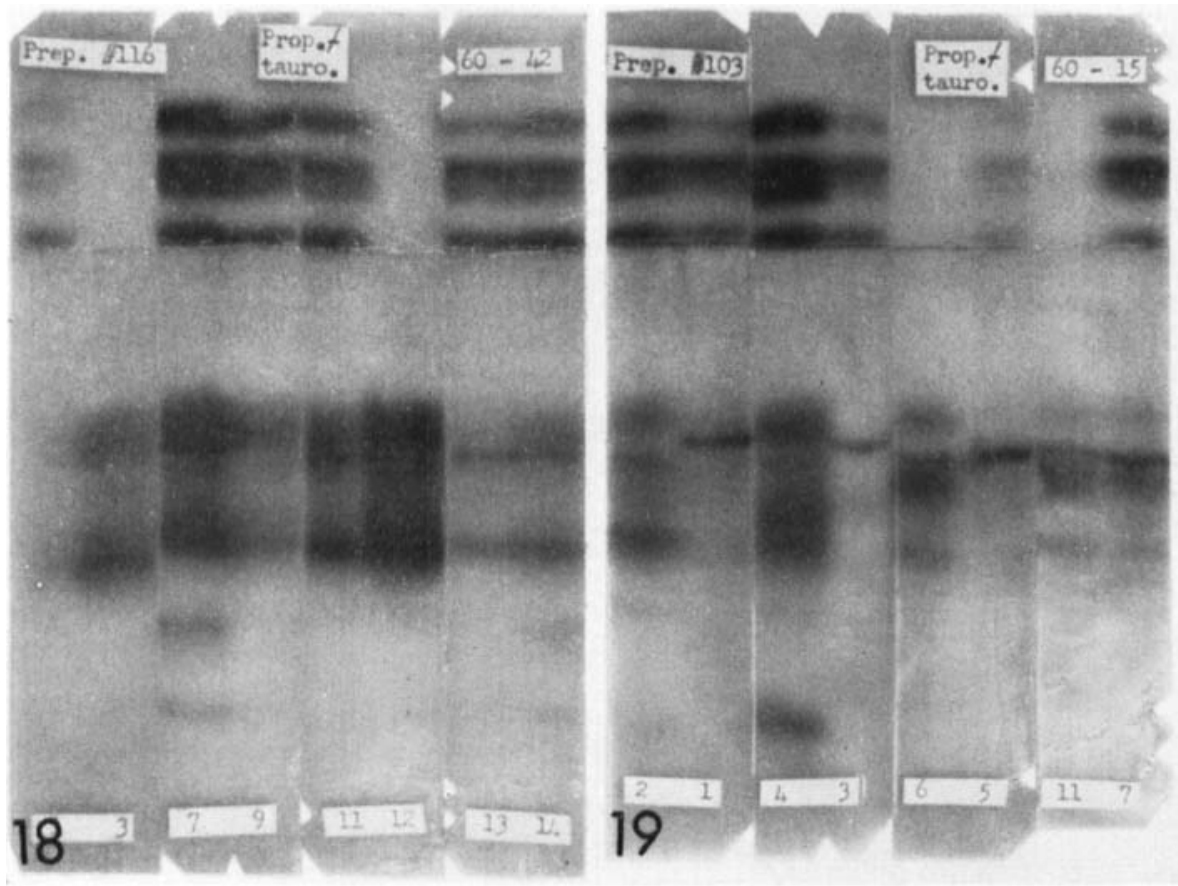

Figure 18. E-1 esterases of $8 \mathrm{~F} 2$ pairs from a cross of F1 (E-1B $\times$ E-1B). Substrate: $\alpha$-naphthyl propionate with sodium taurocholate. Incubated 4 hours.

Figure 19. E-1 esterases of $8 \mathrm{~F} 2$ pairs from a cross of F1 (E-1C $\times$ E-1C). Substrate: $\alpha$-naphthyl propionate with sodium taurocholate. Incubated 4 hours.

random assortment of the differentiated subnuclei to daughter cells during division. The kinetics of segregation were identical for the $m t$ and $H$ loci.

The differentiated cell lines at the $m t$ and $H$ loci were stable only during vegetative reproduction. The differentiated cell lines at the $E-1$ locus were also stable during vegetative reproduction. Tests of the persistence of these differentiations were made by crossing all three phenotypes (E-1B + C, E-1B, E-1C) in all six phenotypic combinations.

Crosses of the most extreme combinations $(\mathrm{E}-1 \mathrm{~B} \times \mathrm{E}-1 \mathrm{~B}$ and $\mathrm{E}-1 \mathrm{C} \times \mathrm{E}-1 \mathrm{C})$ gave rise to pairs of all three classes of phenotypes (FIGURES 18 and 19). This result was obtained regardless of phenotypic combination (TABLE 5). Thus, the differentiations did not persist after conjugation-and all three classes of pairs appeared in the progeny as expected of a cross of two heterozygotes. In 
order to test possible deviations from a $2: 1: 1$ ratio, crosses most similar in character were lumped, since some of the crosses were small. Although qualitative trends are found among different sets of crosses, no set showed a significant departure from a $2: 1: 1$ ratio, nor did the four sets show significant heterogeneity. Hence, the differentiations not only disappear following conjugation but they exert no significant cytoplasmic influence upon the system.

One final observation on the heterozygote should be mentioned, although the data are only suggestive. That is, regardless of phenotype, the total of the activities of the two groups approached a similar value. The totals for individual subclones varied (range 180 to $455 \mathrm{U}$.), but this range undoubtedly reflected differences in protein concentration between preparations. The mean value for $12 \mathrm{E}-1 \mathrm{~B}$ subclones was $300 \mathrm{U}$., for $8 \mathrm{E}-1 \mathrm{C}$ subclones was $240 \mathrm{U}$., and for $44 \mathrm{E}-1 \mathrm{~B}+\mathrm{C}$ subclones was $333 \mathrm{U}$. The lower value for the $\mathrm{E}-1 \mathrm{C}$ subclone

TABLE 5

Crosses of Hybrud Clones with Dirferent E-1 Phenotypes

\begin{tabular}{c|c|c|c|c|c}
\hline \hline \multirow{2}{*}{ Parental phenotypes } & \multicolumn{2}{|c|}{ Esterases of offspring: } & Total No. pairs & Fit to 2:1:1 \\
\cline { 2 - 3 } & B + C & B & C & & \\
\hline (B + C) X (B + C) & 31 & 13 & 16 & 60 & $\mathrm{p}=0.9$ \\
B X (B + C) & 14 & 7 & 2 & 23 & \\
B X B & $\frac{7}{21}$ & $\frac{5}{12}$ & $\frac{4}{6}$ & $\frac{16}{39}$ & $\mathrm{p}=0.5$ \\
C X (B + C) & 2 & 2 & 2 & 6 & \\
C X C & $\frac{20}{22}$ & $\frac{5}{7}$ & $\frac{10}{12}$ & $\frac{35}{41}$ & $\mathrm{p}=0.5$ \\
B X C & 14 & 13 & 10 & 37 & $\mathrm{p}=0.3$ \\
Total & 88 & 45 & 44 & 177 & $\mathrm{p}=0.99$ \\
\hline
\end{tabular}

may not be real because of the way in which Densitometer recordings were measured. A maximum value of light absorption was recorded for each isozyme. Such a procedure would not take into account differences in the width of individual zones in the starch. The E-1C isozymes typically are wider and less distinct than the E-1B isozymes. Thus these maximum values tend to underestimate the E-1C activities. The values of heterozygous clones were similar to those of homozygous clones, with the $\mathrm{E}-1 \mathrm{C}$ homozygote having a slightly lower value.

Additivity of these isozymes toward a similar value, irrespective of genotype and phenotype, suggests that only a certain amount of a protein is made. This suggestion leads to certain speculations concerning the nature of an isozyme, to be discussed below.

\section{Discussion}

The nature of an isozyme. The distinction between a family of enzymes and an isozymic series largely rests upon the degree of specificity which is observed. 
Markert and Møller (1959) defined a family of enzymes as one comprising a group of different enzymes with broad and overlapping substrate specificities. The members of an isozymic series, on the other hand, have a more restricted spectrum of specificity. Observations on the esterases of variety 1 of $T$. pyriformis confirm this distinction. Considerable heterogeneity in enzymatic activities against four substrates and an inhibitor and an activator are found between different members of the family, although many of these members show overlapping specificities. Some of these members are under the control of two unlinked loci. Two of these members are made up of an isozymic series, which show identical specificities under the conditions employed, and the two isozymic sets are under the control of alleles at a single locus.

Only a few genetic studies have been made on the esterases in other organisms. A polygenic mode of inheritance was postulated for the cerebral cholinesterases of the rat (Roderick, 1960). Single gene differences were postulated for piglet arylesterase (Augustinnson and Olsson, 1959), human pseudocholinesterase (Harris et al., 1960) and maize aliesterase (Schwarz, 1960). No genetic studies have as yet been reported on an isozymic series of esterases, but an exciting study is in progress on an isozymic series of alkaline phosphatases in Escherichia coli (Bach et al., 1961).

In $E$. coli starch gel electrophoresis resolved the phosphatases into five electrophoretically distinct components, although a single protein is implicated by Tiselius electrophoresis, sedimentation, and immunological characterization. Chromatographic separation on DEAE cellulose columns showed a single peak, but some heterogeneity of the different isozymes within this peak. Single mutations in the phosphatase gene-or growth under conditions of enzyme repression-eliminated all of the isozymes. Reverse mutations included a number of mutants with altered electrophoretic mobilities, although the number and spacing of the isozymes was retained in the mutants. All the mutants that have been tested genetically show changes within the phosphatase gene. The genetic observations are thus similar to those obtained with the E-1 esterase isozymes in Tetrahymena, although on a much more definitive scale. Quantitative variations in these isozymes were observed with growth on different media similar to the sorts of variations seen in Tetrahymena.

The finding of single gene control of an isozymic set limits speculation concerning the nature of an isozyme, at least in the context of the genetic dogma as it now stands. According to the dogma, a certain prescribed sequence of events transpires from gene to protein: the DNA code is imprinted in RNA, which translates the message into particular amino acid sequences in the protein. These sequences then are supposed to determine a secondary and tertiary structure of the protein. A problem arises in interpreting the electrophoretic differences of a protein with the same enzymatic activity under such a rigid dogma. Markert and Møller (1959) suggested that either "the protein forming mechanism itself is subject to slight structural variations with a consequent variation in its products" or that the protein could be altered by its site of attachment within the cell. The latter interpretation is more consistent with genetic dogma and also certain experimental observations.

Preliminary studies on cell fractions in Tetrahymena suggest that each isozyme may have a different site of attachment within the cell. Observations in 
two other organisms support this idea. Nace et al. found that all four lactic acid dehydrogenase (LDH) isozymes are present in the coelomic eggs of frogs and that two of these isozymes, examined in detail, are localized in different regions of the egg. J. M. Allen, 1961, working with the LDHs of the mouse, was able to localize one of these to the apex of epithelial cells of the body of the epididymis.

A genetic interpretation of this idea was suggested by Levinthal (Spiegelman, 1960). This rests on the assumption that an isozyme is a molecule composed of several proteins. The active site of this molecule could be composed of one polypeptide, the tail of another polypeptide. Since isozymes have similar enzymatic properties, they must contain the same polypeptide in the active site. The tail polypeptides, which would govern the specificity of attachment, could differ, and these could be governed by several different genes.

Such an interpretation would lead to polygenic inheritance for a series of isozymes. Some isozymic series may well turn out to show this type of inheritance, but in at least two cases (Tetrahymena and $E . c o l i$ ) this interpretation works only if the following is assumed: that the strains are isogenic for a gene controlling the polypeptide of the active site and also for genes controlling the tail polypeptides, but that they differ in genes controlling a third polypeptide of unknown biological properties.

Since so many assumptions are needed in order to fulfill this interpretation, two other avenues of approach will be pursued. The first approach adheres to genetic dogma and achieves a way out of the dilemma through polymerization. If a single polypeptide formed polymers of varying size, different specificites of attachment might arise as a consequence of the different tertiary structures of the polymers. The active site, however, must not be affected either by gene substitution or by polymerization. There is evidence for the formation of polymers in systems of this kind in two studies. Smithies (Ingram, 1960) reported that the several electrophoretic components of the haptoglobins in man were stable polymers, which could be resolved into single components by treatment with mercaptoethanol, iodoacetamide, and urea. In maize certain aliesterases are under the control of three alleles at a single locus, and each heterozygote forms a hybrid molecule in addition to the parental molecules (Schwarz, 1960). The amounts of enzymatic activity were additive in the different genotypes, but distributed among each set of components in a manner suggesting that each molecule was a dimer.

The results of Bach $e t$ al., 1961, clearly indicate that different states of aggregation of the phosphatase protein do not occur. A single species of protein is involved and it does not form polymers, yet this protein shows electrophoretic heterogeneity in starch gels. A way out of this dilemma may be found by permitting slight structural variations in the tertiary structure of a protein. Thus the amino acid sequences of a polypeptide would usually result in a certain protein configuration, but in response to different microecological factors, slight deviations in form might be produced. The number of configurations that would be stable would probably be very limited: perhaps by the number of sites of attachment in the cell. These configurations might provide the necessary specificity of attachment to particular sites so that the enzyme would be 
channeled (Vogel, 1955) to particular reaction sequences taking place in different parts of the cell.

Although no data are yet available as to the physicochemical nature of the isozymes in Tetrahymena, the possible additivity of the isozymes in different genotypes suggests that only a certain amount of protein is made, which is then "distributed" among the different isozymes of a group proportionate to the degree of allelic activity in the cell lineage. "Distribution" could mean polymerization or it could mean alteration in configuration of the original molecule.

The different configurations may be involved in the attachment of the enzyme to specific sites within the cell. Differences in activity of an isozyme under various conditions of growth, observed in Tetrahymena and E. coli, could reflect differences in the binding of this isozyme to its site of attachment. Facilitation or interference with this binding would lead to the observation of more or less enzyme becoming attached to a particular site. A corollary of this hypothesis is that certain isozymes in each group might show similar behavior under a given condition of growth. The changes during the growth cycle in Tetrahymena are not so easily explained, but those observed under two other conditions of growth do show correlations. Thus, the cathodal isozymes of each group were more active with growth at $16^{\circ} \mathrm{C}$., while the anodal isozymes of each group were more active with starvation and/or mating.

Nuclear differentiation in Tetrahymena. Previous studies of variety 1 of $T$. pyriformis have implicated the macronucleus and, more specifically, the subnucleus as the locus of nuclear differentiation in this organism (Allen and Nanney, 1958; Nanney and Allen, 1959; Nanney and Dubert, 1960). Analysis of the mating type locus and the $H$ serotype locus showed some features that were different but many features that were remarkably similar.

At each of these loci are a series of alleles. At the $H$ locus each allele determines a ciliary antigen of slightly different specificity at $20-30^{\circ} \mathrm{C}$. (Nanney and Dubert, 1960). At the mating type locus each allele permits the expression of several of the seven mating types, each allele differing in which of the seven types are expressed and the frequencies in which they appear at a particular temperature (Nanney, 1959, 1960a; Nanney et al., 1955). The heterozygote at both these loci has the potentiality of expressing all parental phenotypes.

The phenotypes at both these loci appear to be determined at the level of the caryonide, but this determination is more obvious in the case of the mating types. The correlation of the distributions of the mating types and the new macronuclei within a pair was observed almost 25 years ago by Sonneborn in a related ciliate, Paramecium aurelia (Sonneborn, 1960). Any experimental condition that interfered with the formation or distribution of new macronuclei resulted in alteration of the appearance or frequency of a mating type. Thus, it was concluded that the new macronuclei become differentiated during their formation, so that they control different phenotypes.

A more precise localization of the control of the mating types was demonstrated in Tetrahymena. Certain caryonides are unstable and mixed in phenotype (Nanney and Caughey, 1955; Allen and Nanney, 1958). They give rise to cell lines that are also unstable and to two or more cell lines that are stable for 
different mating types. An analysis of unstable caryonides giving rise to two stable lines showed that the kinetics of formation of the stable lines were the same, regardless of the two types that were present. At equilibrium the total rate of fixation was found to be 0.0113 per fission and the two types were produced at equal rates. These results were consistent with a particulate segregation model that assumed that the macronucleus consisted of diploid subnuclei, which could differentiate and give rise to a heterogeneous macronucleus. Random segregation of these differentiated subnuclei to daughter macronuclei would occasionally lead to the production of a macronucleus pure for one type of subnucleus. Such cell lines would be stable. The rate per fission $\left(R_{f}\right)$ at which stable lines are produced was shown by Schensted (1958) to be related to the total number $(N)$ of subnuclei in the macronucleus; thus $R_{f}=1 /(2 N-1)$. Where $R_{f}=0.0113$, the number of subnuclei in a newly divided cell is 45 .

Similar observations were made on heterozygotes at the $H$ locus (Nanney and Dubert, 1960). Heterozygous caryonides are unstable and give rise to cell lineages, some of which are unstable and express both alleles at the $B$ locus, and others which are stable and express only one of the two alleles. The rate of formation of these stable cell lines was identical to that determined for the mating type system.

An analysis of the $H$ heterozygote suggests that the site of nuclear differentiation in Tetrahymena is not only localized within the subnucleus but to the chromosomes themselves. One allele in each subnucleus of a heterozygote is suppressed, but which allele is expressed varies in different subnuclei. Cells with heterogeneous macronuclei express both alleles and are unstable. Cells with macronuclei containing subnuclei all suppressed for the same allele, express the other allele and are stable.

Differentiation occurs only in heterozygotes at the $H$ locus. At the $m t$ locus differentiation also occurs in homozygotes, and as many as four phenotypes may occur in different cell lineages of a single caryonide. As Nanney and Dubert (1960) point out, this observation makes gene segregation within the macronucleus very improbable and supports the hypothesis that the differentiations occur in different diploid subnuclei.

The differentiations at both the $m t$ and $H$ loci are permanent during the remainder of the vegetative existence of the cell. Those at the $B$ locus even persist after a period of exposure to conditions that result in the nonfunctioning of the $H$ locus. However, the differentiations at both the $m t$ and $H$ loci do not persist after conjugation.

Many features of the $m t$ and $H$ loci are shared by the $E-1$ locus. Like the $H$ locus, the two alleles at the $E-1$ locus, when present in a heterozygote, vary in expression within a caryonide. Unstable cell lineages, which express both alleles, give rise to stable cell lines expressing only one of the two alleles. Adequate kinetic data are lacking for the $E-1$ locus, but the observations on heterozygous clones showing that they varied qualitatively and quantitatively in their capacity to produce stable cell lines are consistent with crude observations made on the mating type and serotype systems. Like the differentiations at the $m t$ and $H$ loci, those at the $E-1$ locus persist only during vegetative reproduction.

An analysis of vegetative assortment at the $m l$ and $H$ loci showed that each 
system is independent of the other (Nanney, 1960b). They are unlinked genetically as well as phenotypically. These two systems (and probably the E-1 esterases, too) converge only in that their site of differentiation-the subnucleus - is the same. Hence, their common kinetic properties arise from a common physical organization of the subnuclei within the macronucleus. The secret of the control of these individual phenotypes lies within these subnuclei: probably on the chromosomes themselves.

Cellular differentiation and isozymes. Cellular differentiation results in striking differences in patterns of activity of the LDH isozymes (Markert and Møller, 1959; Tsao, 1960). Different patterns were observed between similar adult tissues and tissue cultures of different species, between different adult tissues of the same species, and between similar adult and embryonic tissues of the same species. Changes in pattern of esterase activity were also observed during ontogeny in mouse tissues (Markert and Hunter, 1959). Contrary to these findings, only quantitative differences in the activity of the esterase isozymes were observed between cells of the same genotype in Tetrahymena (Allen, 1960a). Clonal analyses revealed that all the isozymes of a group (or groups) were present in the cells of the three genotypes.

In higher organisms some of the isozymic changes during ontogeny could be due to differential gene activity where a polygenic mode of inheritance is implicated. In these cases it is simplest to assume two states for a gene: either it is "on" or it is "off". A given pattern of cellular differentiation would then result from a certain combination of genes that are "on". Where single gene control is involved, the isozymic changes could reflect interference at several different points in the sequence from gene to protein.

In Tetrahymena several different phenotypes are often associated with a single genotype and, in the cases examined, the control of these differences resides within the subnucleus and is probably chromosomal. It is possible that interference with DNA occurs, perhaps in its association with RNA or nuclear proteins, to give rise to several different states of a gene besides its "on" or "off" states. Nanney (1960a) speculated that different folding configurations of material associated with the chromosomes could give rise to several molecular species, each of which could ultimately give rise to a different phenotype. These configurations might replicate-along with the chromosomeduring the vegetative existence of the cell, but they would be eliminated at the onset of meiosis. Brink (1960) suggested that one of the prime functions of meiosis might be to strip the chromosomes of associated materials acquired during the vegetative life of the cell.

A similar type of control may be exerted in some of the isozymic series, if nuclear differences can be demonstrated. However, for systems that do not show nuclear differences - as in the case of the esterase isozymes in Tetrahymena-the level of control appears to be further removed from the gene. In such systems some type of control may be exerted on the channeling of particular isozymes to their sites of attachment within the cell. Microecological differences arising from different cellular associations and environments could determine the stability of particular configurations and the configurations at the attachment sites. Under certain conditions these configurations could persist with a high degree of stability. 


\section{Summary}

The esterases of variety 1 of $T$. pyriformis can be resolved into a number of zones by starch gel electrophoresis. These zones can be separated into two classes on the basis of substrate specificity and reaction to eserine sulfate and sodium taurocholate. At $p \mathrm{H} 7.5$ to 9.5 one of these classes includes two groups of isozymes, which have similar substrate specificities and are inhibited by eserine and activated by taurocholate. The $B$ group of isozymes is found in inbred strains A, B, and D, while the C group is limited to strain C. Each group of isozymes functions as a unit during vegetative and sexual reproduction. Isozymic activities vary under different growth conditions and, as preliminary studies indicate, in different parts of the cell.

Crosses between $\mathbf{B}$ and $\mathbf{C}$ cells produce hybrids with both groups of isozymes $(B+C)$. However, hybrids vary within the clone in their expression of the two groups, and subclones phenotypically $\mathrm{B}$ or $\mathrm{C}$ can be selected. Hybrids, in various phenotypic combinations, when intercrossed, give rise to three classes of $\mathrm{F} 2$ pairs, $\mathrm{B}+\mathrm{C}, \mathrm{B}$ and $\mathrm{C}$ in a 2:1:1 ratio. Backcrossed to parental cells, only two classes appear, $\mathrm{B}+\mathrm{C}$ and $\mathrm{B}$ (or $\mathrm{C}$ ) in a $1: 1$ ratio. Thus the two groups of isozymes are controlled by alleles at a single locus $(E-1)$. A homozygote expresses only the $\mathrm{B}$ or only the $\mathrm{C}$ group. A heterozygote has the potentiality of expressing both groups, but it becomes differentiated (probably by allelic suppression) so that it expresses either the $\mathrm{B}$ or the $\mathrm{C}$ group. These differentiations persist only during the vegetative life of the cell.

Evidence will also be presented for a second locus $(E-2)$ governing two members of the other class of esterases. $E-1$ and $E-2$ appear to be unlinked loci.

Since a single gene was implicated in the control of a set of isozymes, a single protein appears to be involved. This inference leads to certain speculations concerning the structure and function of an isozyme. An isozyme could arise either by polymerization or by structural alteration of a single protein. These configurations could endow the isozymes with differences in specificity necessary for their attachment to certain sites in the cell as a prerequisite for their function in particular reaction sequences.

\section{Acknowledgment}

I gratefully acknowledge the technical assistance of Keith A. Arnold, Robert A. Berkoff, and Rita G. Dy.

\section{References}

AlLEN, J. M. 1961. Multiple forms of lactic dehydrogenase in tissues of the mouse, their specificity, cellular localization and response to altered physiological conditions. Ann. N.Y. Acad. Sci. 94: 937-951

Allen, S. L. 1958. Cytochemical localization of enzymes in sexual strains of the Protozoan, Telrahymena pyriformis. Anat. Record. 131: 526-527.

Allen, S. L. 1960a. Inherited variations in the esterases of Tetrahymena. Genetics. 45: $1051-1070$.

AlLEN, S. L. $1960 b$. Abnormal segregation at the mating type locus in variety 1 of Tetrahymena pyriformis. J. Protozool. 7(Suppl.): 15.

Allen, S. L. \& D. L. NANNEY. 1958. An analysis of nuclear differentiation in the selfers of Tetrahymena. Am. Naturalist. 92: 139-160.

Augustinnson, K.-B. \& B. Olsson. 1959. Esterases in the milk and blood plasma of swine. 2. Activities at different stages during the lactation and suckling periods, and plasma arylesterase as a gene-controlled enzyme. Biochem. J. 71: 484-492. 
Bach, M. L., E. R. Signer, C. Levinthat \& I. W. Sizer. 1961. The electrophoretic patterns of alkaline phosphatase from various $E$. coli mutants. Federation Proc. 20: 225.

Brink, R. A. 1960. Paramutation and chromosome organization. Quart. Rev. Biol. 36: $120-137$.

Harris, H., M. Whittaker, H. Lehmann \& E. Silk. 1960. The pseudocholinesterase variants. Fsterase levels and dibucaine numbers in families selected through suxamethonium sensitive individuals. Acta Genet. et Statist. Med. 10: 1-16.

Hunter, R. L. \& C. L. MARkERT. 1957. Histochemical demonstration of enzymes separated by zone electrophoresis in starch gels. Science. 125: 1294-1295.

IngraM, V. M. 1960. The genetic control of protein structure. In Genetics: Genetic Information and the Control of Protein Structure and Function. : 65-176. H. E. Sutton, Fd. Josiah Macy, Jr. Foundation. New York, N.Y.

Levinthal, C. 1960. Discussion in S. Spiegelman. Factors modulating the biochemical expression of genetic systems. : 189-190. In Genetics: Genetic Information and the Control of Protein Structure and Function. H. E. Sutton, Ed. Josiah Macy, Jr. Foundation. New York, N.Y.

Markert, C. L. \& R. L. Hunter. 1959. The distribution of esterases in mouse tissues. J. Histochem. Cytochem. 7: 42-49.

MARkert, C. L. \& F. M $\varnothing$ LLER. 1959. Multiple forms of enzymes: tissue, ontogenetic, and species specific patterns. Proc. Natl. Acad. Sci. U.S. 45: 753-763.

Nace, G. W., T. Suyama \& N. Smith. Early development of special proteins. Symposium of Internal Inst. of Embryol. Pallanza, Italy. In press.

Nanney, D. I. 1958. Epigenetic control systems. Proc. Natl. Acad. Sci. U.S. 44: 712-717.

NANNEY, D. L. 1959. Genetic factors affecting mating type frequencies in variety 1 of Tetrallymena pyriformis. Genetics. 44: 1173-1184.

Nanney, D. L. $1960 a$. Temperature effects on nuclear differentiation in variety 1 of Telrahymena pyriformis. Physiol. Zoöl. 33: 146-151.

NAnney, D. L. 1960b. The relationship between the mating type and the $\mathrm{H}$ serotype systems in Tetrahymena. Genetics. 45: 1351-1358.

Nanney, D L. \& S. L. Allen. 1959. Intranuclear co-ordination in Tetrahymena. Physiol. Zoöl. 32: 221-229.

Nanney, D. I. \& P. A. Caughey. 1955. An unstable nuclear condition in Tetrahymena pyriformis. Genetics. 40: 388-398.

Nanney, D. L., P. A. Caughey \& A. TefankJian. 1955. The genetic control of mating type potentialities in Tetrahymena pyriformis. Genetics. 40: 668-680.

Nanney, D. L. \& J. M. Dubert. 1960. The genetics of the H serotype system in variety 1 of Tetrahymena pyriformis. Genetics. 45: 1335-1349.

Preer, J. R., Jr. \& L. B. Preer. 1959. Gel diffusion studies on the antigens of isolated cellular components of Paramecium. J. Protozool. 6: 88-100.

RODERICK, T. H. 1960. Selection for cholinesterase activity in the cerebral cortex of the rat. Genetics. 45: 1123-1140.

Schensted, I. V. 1958. Appendix: model of subnuclear segregation in the macronucleus of ciliates. Am. Naturalist. 92: 161-170.

SchWARz, D. 1960 . Genetic studies on mutant enzymes in maize: synthesis of hybrid enzymes by heterozygotes. Proc. Natl. Acad. Sci. U.S. 46: 1210-1215.

Seaman, G. R. 1951. Localization of acetylcholinesterase activity in the protozoan, Tetrahymena geleii S. Proc. Soc. Exptl. Biol. Med. 76: 169-170.

Smithies, O. 1960. Discussion in V. M. Ingram. The genetic control of protein structure. In Genetics: Genetic Information and the Control of Protein Structure and Function. : 129-136. H. E. Sutton, Ed. Josiah Macy, Jr. Foundation. New York, N.Y.

Sonneborn, T. M. 1957. Breeding systems, reproductive methods and species problems in protozoa. In The Species Problem. : 155-324. E. Mayr, Ed. A.A.A.S. Symposium. Washington, D.C.

Sonneborn, T. M. 1960. The gene and cell differentiation. Proc. Natl. Acad. Sci. U.S. 46: $149-165$.

Spiegelman, S. 1960. Factors modulating the biochemical expression of genetic systems. In Genetics: Genetic Information and the Control of Protein Structure and Function. : 177-218. H. E. Sutton, Ed. Josiah Macy, Jr. Foundation. New York, N.Y.

TSAO, M. U. 1960. Heterogeneity of tissue dehydrogenases. Arch. Biochem. Biophys. 90: $234-238$

VogEL, H. J. 1955. On the glutamate-proline-ornithine interrelation in various microorganisms. In A Symposium on Amino Acid Metabolism. : 335-346. W. D. McElroy \& H. B. Glass, Eds. The Johns Hopkins Press. Baltimore, Md.

Watson, J. D. 1960 . Current concepts of the fine structure of chromosomes and the nature of the coding mechanism. In Genetics: Genetic Information and the Control of Protein Structure and Function. : 11-64. H. E. Sutton, Ed. Josiah Macy, Jr. Foundation. New York, N.Y. 